\title{
Analysis of the Effect of Spring on the Force Behavior of Cable Net
}

\author{
LI Ming ${ }^{1,2, a^{*}}$, YAN Wei ${ }^{2, b}$, WANG Yuanqing ${ }^{3}$, TAo Wei ${ }^{2}$, LI Shoukun ${ }^{2}$, \\ SHAN Renliang ${ }^{4}$
}

${ }^{1}$ Civil Engineering College, Shenyang Jianzhu University, Shenyang, China;

2Jangho Group Co., Ltd. Beijing, China

${ }^{3}$ Civil Engineering College, Tsinghua University Beijing, China

${ }^{4}$ Civil Engineering and Mechanics, China University of Mining \&Technology, Beijing, China

adingxianxing@126.com, ${ }^{b} 717185751 @ q q . c o m$

Keywords: Spring; Cable Net; Stiffness; Prestress; Maximum Deflection

Abstract. At present, rarely research is done about the loading process of cable net curtain wall with spring mechanism, therefore, how to select the spring stiffness at the cable end and what role the spring play in the process of loading become the very concern for curtain wall designers. Therefore, based on the early cable net computing model of a building-Beijing Olympic Project Tower 3, the influence of spring stiffness on the force performance of cable net is analyzed with the condition that the external load and cable prestress unchanged. It shows that: under the same external load, the smaller the spring stiffness is, the lower the axial force of vertical cable and the vertical bearing reaction force is, which is better to meet the bearing capacity of vertical cable and the main structure connected with it, and increase the axial force of horizontal cable, the maximum deflection and the initial prestress of the vertical cable; the smaller the spring stiffness is, the more uneven the internal force of the vertical cable is, which is only influenced by the gravity load taken by vertical cable, and has no relation with the initial prestress and the change of deflection; the smaller the spring stiffness, the larger part the spring take in the whole bearing process.

\section{Introduction}

Beijing Olympic Project Tower 3 is a super-rise high building. The structure form of it is steel reinforcement concrete column steel frame-steel reinforcement concrete core tube. It is proposed to adopt double plane cable net point supported glass curtain wall at the top of the building. The elevation of the curtain wall is from $143 \mathrm{~m}$ to $165 \mathrm{~m}$, and steel pipe is adopted to connect the double cables at horizontal direction. In the early design scheme: the indoor vertical cable of the double cable is $16.75 \mathrm{~m}$ long, and its diameter is $38 \mathrm{~mm}$, and its broken force is $968.37 \mathrm{kN}$, and it's design bearing capacity is $538 \mathrm{kN}$; the outdoor vertical cable of the double cable is $21.3 \mathrm{~m}$ long, and its diameter is $28 \mathrm{~mm}$, and its broken force is $526.48 \mathrm{kN}$, and it's design bearing capacity is $292 \mathrm{kN}$; the outdoor horizontal cable of the double cable is the same with the outdoor vertical cable except its $43.15 \mathrm{~m}$ in length. The cable net curtain wall is located at the top of the structure, and has large span. In order to reduce the cable slack caused by the main structure deformation, it is proposed to set up spring mechanism at the top end of cable. Plane cable net supported curtain wall is widely used, but rarely research is done about the loading process of cable net curtain wall with spring mechanism [1-4], therefore, how to select the spring stiffness at the cable end and what role the spring play in the process of loading become the very concern for curtain wall designers. Therefore, it's discussed how to select spring stiffness and what role the spring play in the process of cable force. 


\section{Calculation model}

In the calculation model, the spring is directly established in the overall model as the form of spring support, and the other cable ends are constrained by hinged support. The overall model is shown in Fig.1 (left). In order to analyze the influence of spring stiffness on the force performance of cable net, a slice of cable net is selected as the typical single common cable for analysis, shown in Fig. 1 (right). Load mainly include the prestress, constant load, wind load and temperature load.
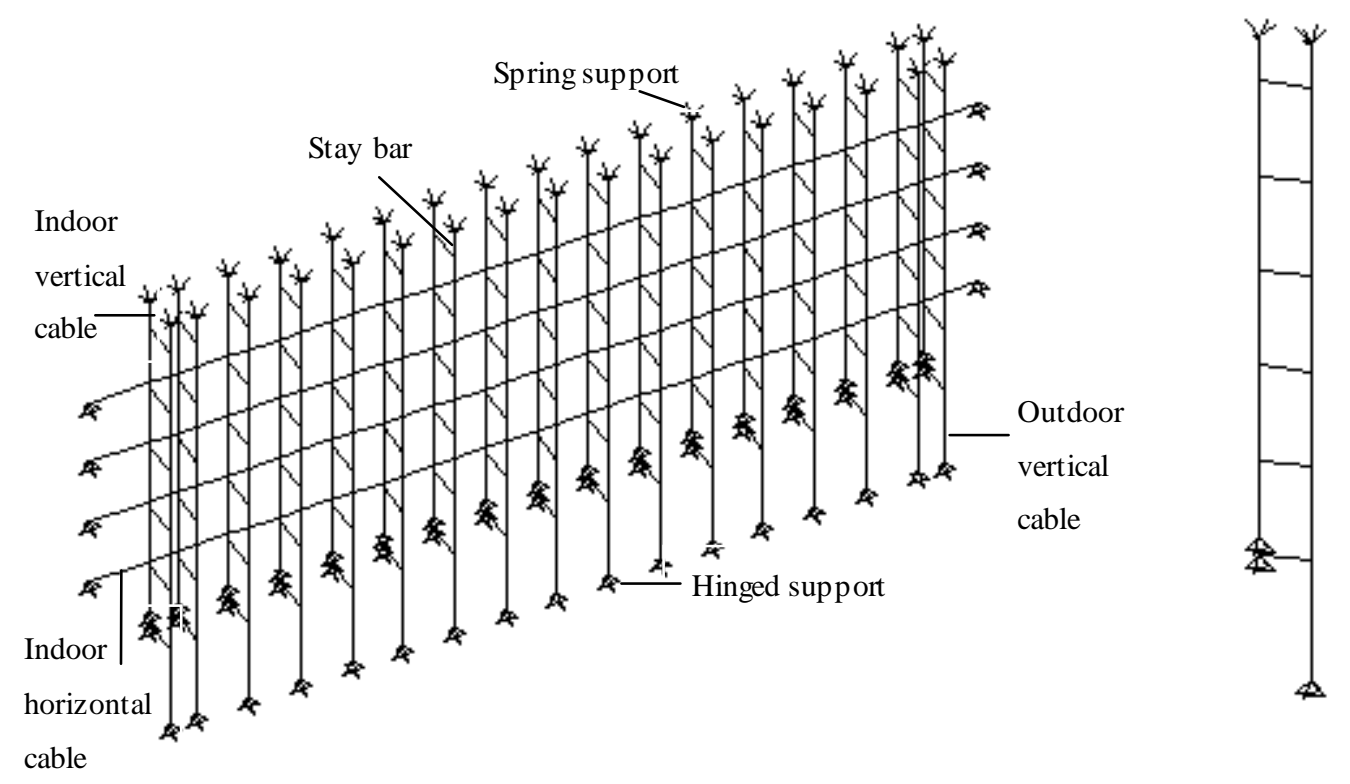

Fig.1 Overall model of double plane cable net (left) model and single common cable (right)

\section{Influence of spring stiffness on force performance of cable net}

Design of spring stiffness. Lijie Y, Junjin L \& Ping Hanalyzed the working principle of spring mechanism with a simplified single cable model under the action of axial force [2]. The result show that the ratio of cable stiffness to spring stiffness should be greater than 4 and less than 10 to realize fluctuation of reducing impaction. The conclusion provides a useful reference for the design of our project. But because the result is only concerned with a simplified model of a cable and spring under the axial load, not considering the influence of horizontal force and horizontal cable, it cannot be directly applied to our project. In order to analyses how the spring stiffness affect the structural behavior of cable net system, we design the spring stiffness according to line stiffness of indoor and outdoor vertical cable. The stiffness ratio of spring to cable is respectively $1 / 4,1 / 2,1,2,4,8$, and $\infty$, of which $\infty$ means the spring stiffness is infinite, i.e. it's hinged support on the main structure. Spring stiffness is shown in Tab.1.

Influence of spring stiffness on the force performance of cable net system. Under the condition of same external load, the prestress of indoor vertical cable is set to $350 \mathrm{kN}$, the prestress of outdoor vertical cable is set to $120 \mathrm{kN}$, the prestress of indoor horizontal cable $100 \mathrm{kN}$. Keeping the prestress unchanged, we calculate the corresponding cable force and deformation at the different stiffness ratio, shown in Tab. 2. Then keeping the maximum deflection of cable net $335 \mathrm{~mm}$ unchanged, we calculate the corresponding cable force and deformation at the different stiffness ratio, shown in Tab. 3. In the Table, (1)represents indoor vertical cable, (2) represents outdoor cable, (3)represents indoor horizontal cable. 
Tab. 1. Designed spring stiffness

\begin{tabular}{ccc}
\hline Ratio of spring to cable & outdoor & indoor \\
\hline$\infty$ & $\infty$ & $\infty$ \\
8 & 48880 & 20896 \\
4 & 24440 & 10448 \\
2 & 12220 & 5224 \\
1 & 6110 & 2612 \\
$1 / 2$ & 3055 & 1306 \\
$1 / 4$ & 1527.5 & 653 \\
\hline
\end{tabular}

Tab. 2. Calculation results on the condition that prestress is unchanged

\begin{tabular}{|c|c|c|c|c|c|c|c|c|c|c|c|c|c|}
\hline \multirow{3}{*}{$\begin{array}{l}\text { Stiffness } \\
\text { ratio }\end{array}$} & & \multirow{3}{*}{$\begin{array}{l}\text { Max } \\
\text { axial } \\
\text { force } \\
(\mathrm{kN})\end{array}$} & \multirow{3}{*}{$\begin{array}{l}\text { Min } \\
\text { axial } \\
\text { force } \\
(\mathrm{kN})\end{array}$} & \multirow{3}{*}{$\begin{array}{l}\text { Axial } \\
\text { force } \\
\text { ratio }\end{array}$} & \multirow{3}{*}{$\begin{array}{c}\text { Max } \\
\text { deflecti } \\
\text {-on } \\
(\mathrm{mm})\end{array}$} & \multicolumn{2}{|c|}{ Support spring $(\mathrm{mm})$} & \multicolumn{6}{|c|}{ Support reaction $(\mathrm{kN})$} \\
\hline & & & & & & \multirow{2}{*}{$\begin{array}{c}\text { Max } \\
\text { deform- } \\
\text { ation }\end{array}$} & \multirow{2}{*}{$\begin{array}{c}\text { Deformation } \\
\text { difference }\end{array}$} & \multicolumn{2}{|c|}{ Cable top } & \multicolumn{2}{|c|}{ Cable bottom } & \multicolumn{2}{|c|}{ Horizontal cable } \\
\hline & & & & & & & & YD & $\mathrm{ZD}$ & YD & ZD & $\mathrm{XD}$ & YD \\
\hline \multirow{4}{*}{$\infty$} & (1) & 546 & 524 & $96 \%$ & 342 & 0 & 0 & 48 & 544 & 48 & 520 & - & - \\
\hline & (2) & 254 & 170 & $67 \%$ & 342 & 0 & 0 & 35 & 253 & 35 & 165 & - & - \\
\hline & (3) & 166 & 165 & $99 \%$ & 342 & - & - & - & - & - & - & 165 & 20 \\
\hline & (1) & 533 & 511 & $96 \%$ & 350 & 11 & 4 & 48 & 531 & 48 & 507 & - & - \\
\hline \multirow[t]{3}{*}{8} & (2) & 243 & 160 & $66 \%$ & 350 & 12 & 4 & 35 & 243 & 35 & 155 & - & - \\
\hline & (3) & 169 & 167 & $99 \%$ & 350 & - & - & - & - & - & - & 187 & 20 \\
\hline & (1) & 522 & 500 & $96 \%$ & 357 & 21 & 6 & 49 & 520 & 49 & 496 & - & - \\
\hline \multirow[t]{3}{*}{4} & (2) & 235 & 152 & $65 \%$ & 357 & 22 & 7 & 34 & 234 & 34 & 147 & - & - \\
\hline & (3) & 171 & 169 & $99 \%$ & 357 & - & - & - & - & - & - & 169 & 21 \\
\hline & (1) & 504 & 481 & $95 \%$ & 369 & 41 & 12 & 49 & 501 & 49 & 477 & - & - \\
\hline \multirow[t]{3}{*}{2} & (2) & 222 & 139 & $63 \%$ & 369 & 42 & 13 & 34 & 221 & 34 & 134 & - & - \\
\hline & (3) & 175 & 173 & $99 \%$ & 369 & - & - & - & - & - & - & 173 & 22 \\
\hline & (1) & 478 & 456 & $95 \%$ & 389 & 78 & 20 & 49 & 476 & 49 & 452 & - & - \\
\hline \multirow[t]{3}{*}{1} & (2) & 204 & 122 & $60 \%$ & 389 & 78 & 24 & 34 & 203 & 34 & 116 & - & - \\
\hline & (3) & 180 & 179 & $99 \%$ & 389 & - & - & - & - & - & - & 179 & 24 \\
\hline & (1) & 450 & 427 & $95 \%$ & 405 & 146 & 30 & 50 & 447 & 50 & 423 & - & - \\
\hline \multirow[t]{3}{*}{0.5} & (2) & 185 & 103 & $56 \%$ & 405 & 141 & 37 & 33 & 184 & 33 & 98 & - & - \\
\hline & (3) & 187 & 185 & $99 \%$ & 405 & - & - & - & - & - & - & 185 & 27 \\
\hline & (1) & 421 & 398 & $95 \%$ & 427 & 273 & 42 & 51 & 418 & 53 & 393 & - & - \\
\hline \multirow[t]{2}{*}{0.25} & (2) & 166 & 85 & $51 \%$ & 427 & 252 & 54 & 32 & 165 & 25 & 79 & - & - \\
\hline & (3) & 195 & 193 & $99 \%$ & 427 & - & - & - & - & - & - & 193 & 28 \\
\hline
\end{tabular}

* Note: XD, YD, ZD means 'X direction', 'Y direction' and 'Z direction' separately.

The influence of spring stiffness on the maximum and minimum axial force. From Tab. 2, it can be concluded that when vertical prestress is unchanged, with the increase of spring stiffness, the maximum and minimum axial force of indoor and outdoor cable both increase, and the maximum and minimum axial force of horizontal cable reduce, and the maximum deflection of vertical and horizontal cable both reduce. It can be concluded that the smaller the spring stiffness, the smaller 
the vertical axial force, the better for vertical cable to meet design requirement of bearing capacity. But at the same time this increases the axial force of horizontal cable, deflection of the whole cable net system or the prestress of vertical cable.

The influence of spring stiffness on the support reaction of cable. From Tab. 2, it can be known that when vertical prestress is unchanged, with the increase of spring stiffness, the support reaction of indoor and outdoor vertical cable in $\mathrm{ZD}$ increases, and the support reaction in YD decreases, while the support reaction of the horizontal cable in both XD and YD decrease, but the difference is small. It can be concluded that the smaller the spring stiffness, the smaller the support reaction of vertical cable in $\mathrm{ZD}$, the better to meet the requirement of bearing capacity of main structure connected to vertical cable.

The influence of spring stiffness on the internal force uniformity of cable. From Tab. 2 and 3 , it can be known that with the increase of spring stiffness, the ratio of minimum to maximum axial force of both indoor and outdoor vertical cable increase, while the ratio of horizontal cable basically remain unchanged which illustrate that the smaller the spring stiffness is, the greater the gravity load sustained by vertical cable, and the internal force is relativity more uneven, but the uneven degree has nothing to do with the prestress and maximum deflection change of vertical cable.

The influence of spring stiffness on the whole force of the cable net system. From Tab. 2 it can be concluded that the smaller the spring stiffness is, the greater the degree that spring participates in the whole force of cable net. On the contrary, when the stiffness ratio is large enough, the spring will play a small role being closed to hinged support.

Values of spring stiffness to meet the design requirement. According to the design requirement, the design bearing capacity of indoor vertical cable is $538 \mathrm{kN}$, the design bearing capacity of indoor horizontal cable and outdoor vertical cable is $292 \mathrm{kN}$, and the maximum deflection limit of cable net $335 \mathrm{~mm}$. At the same time in order to make sure that the spring participate in the force of the whole cable net system, the spring support need to has a certain deformation difference. According to the above requirements, it can be known that when the stiffness ratio of spring is " 4 " in Tab. 2 , it can meet the design requirement.

\section{Conclusions}

From the above analysis, it can be concluded:

(1) When the external load and the prestress of vertical cable is unchanged, with the decrease of spring stiffness, the axial force and vertical bearing reaction of vertical cable both reduce. This is beneficial to meet the design requirements of bearing capacity of vertical cable and the main structure connected to it. But at the same time, it can also cause the increase of the axial force of horizontal cable, and the increase of the maximum deflection and initial prestress of the vertical cable.

(2) With the decrease of the stiffness ratio of spring to vertical cable, the internal force of vertical cable will become more uneven, and the uneven degree is mainly related with the gravity load sustained by the vertical cable, and has nothing to do with the change of the prestress. The smaller the stiffness ratio of spring to vertical cable, the greater the degree that spring participate in the whole force. 


\section{Acknowledge ment}

This work was financially supported by China Postdoctoral Science Foundation funded project (2014M560938) and Beijing Postdoctoral Research Foundation funded project.

\section{References}

[1] Chang S. Bearing performance and the engineering application research on point supported glass curtain wall single cable support system. Master's degree thesis of Tsinghua University, 2012.

[2] Lijie Y, Junjin L \& Ping H. The Application of spring mechanism on the glass curtain wall supporting system, J. Volume 27(2011): 76-79.

[3] Yong L, Yongjiu S, Yuanqing W, Yi L \& Yue X. Beijing Tucheng Telephone Station anti-seismic design method on single-layer cable net-point glass curtain wall, J.Volume 31(2009): 112-117.

[4] Yuanqing W, Fen S, Yongjiu S \& Lili W. The effect of glass and node constraint on the bearing performance of single-layer cable net, J. Volume 39(2011): 1309-1313. 